\title{
Comparison of laser welds in thick section S700 high-strength steel manufactured in flat $(1 G)$ and horizontal $(2 G)$ positions
}

\author{
Wei Guo ${ }^{\mathrm{a}, *}$, Qiang Liu ${ }^{\mathrm{a}}$, John A. Francis ${ }^{\mathrm{a}}$, Dave Crowther ${ }^{\mathrm{b}}$, Alan Thompson ${ }^{\mathrm{b}}$, Zhu Liu ${ }^{\mathrm{c}}$, Lin Li (1) ${ }^{\mathrm{a}}$ \\ ${ }^{a}$ Laser Processing Research Centre, School of Mechanical, Aerospace and Civil Engineering, The University of Manchester, Sackville Street, Manchester M13 9PL, UK \\ ${ }^{\mathrm{b}}$ Tata Steel, Research \& Development, Swinden Technology Centre, Moorgate, Rotherham, South Yorkshire S60 3AR, UK

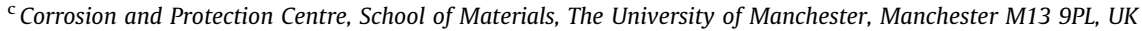

\section{A R T I C L E I N F O}

\section{Keywords:}

Laser

Welding

High strength steel

\begin{abstract}
A B S T R A C T
Lack of penetration, undercut and melt sagging are common welding defects for single-pass laser welds in thick plates, particularly when using a traditional $1 \mathrm{G}$ welding position (laser directed towards ground). This investigation shows, for the first time, that welding $13 \mathrm{~mm}$ thick high-strength S700 steel plates in the $2 \mathrm{G}$ position (laser beam perpendicular to the direction of gravity) can mitigate some of the common welding defects including undercut and sagging. A computational fluid dynamic analysis indicates that the $2 \mathrm{G}$ welding position can assist in achieving an appropriate balance between surface tension, hydrostatic pressure (gravity) and recoil-pressure from the metal vapour.
\end{abstract}

(c) 2015 CIRP.

\section{Introduction}

High strength low alloy (HSLA) steels have been widely used for many years, due to their high strength and toughness. HSLA steels are used in a variety of applications such as in structural components, pressure vessels and fluid transportation pipes, in shipbuilding, offshore construction, automotive applications, and lifting and handling equipment [1,2]. The application of HSLA steels enables lighter and more slender products to be employed and reduces construction costs without loss of structural integrity [3]. Recently, fibre laser welding has been receiving attention due to the advantages of high power, high beam quality, flexible optical fibre beam delivery, and high energy efficiency, which enable high penetration welds to be produced at fast welding speeds $[4,5]$. During solidification of the weld pool, the longitudinal and transverse shrinkage stress variations along the keyhole axis are much lower than for most other welding technologies. This results in low buckling and bending of the workpieces [6].

There are several common defects in laser welding of thick section materials: lack of penetration, undercut on the top weld surface and melt sagging at the root section of the weld, which occur in single-pass welding of thick metallic plates in the flat welding position (i.e. $1 \mathrm{G}$, with the laser beam facing towards the ground) due to imbalances of the surface tension and the hydrostatic pressure in the melt pool [7].

A backing plate is often employed to prevent the molten pool sagging excessively [8]. Jones et al. [9] took advantage of the electromagnetic (Lorentz) force in an electrically conducting liquid metal to compensate for the force of gravity and support the weld pool during overhead electron beam welding. The excitation

\footnotetext{
* Corresponding author.

E-mail address: wei.guo-2@manchester.ac.uk (W. Guo).
}

devices were placed below the weld to generate the upward Lorentz force in order to support the weight of the molten pool. The idea to use this Lorentz force in high power laser beam welding of $20 \mathrm{~mm}$ thick stainless steel plates, in the $1 \mathrm{G}$ position, was developed in Bachmann et al.'s [7] work. However, the equipment and application of the Lorentz force technique can be complex, and it can be difficult to remove a backing plate after welding.

Welding in the horizontal (2G) position plays an important role in the manufacture of large and heavy structures, and in some cases it is the only viable welding position. However, there is a lack of understanding of autogenous laser welding in the $2 \mathrm{G}$ position, particularly for the welding of thick section materials.

There have been very few investigations on $2 \mathrm{G}$ position laser welding. In order to investigate the relationships between penetration depth and welding parameters in the welding of thick plates, Okado et al. [10] and Wani et al. [11] developed a combined laser system using a $6 \mathrm{kWYAG}$ laser and a $10 \mathrm{~kW}$ Chemical Oxygen-Iodine Laser (COIL). This system was used for bead-on-plate welding tests on thick 304 stainless steel and aluminium alloy plates in the 2G welding position. However, they did not explore the physics of thick section autogenous laser welding in the $2 \mathrm{G}$ position.

This paper compares the characteristics of high power fibre laser welding of thick section S700 high strength steel in the 1G and $2 \mathrm{G}$ positions, for the first time, filling some of the knowledge gaps in the understanding of weld defect formation. In particular, computational fluid dynamic (CFD) modelling was carried out to understand the dynamic forces on the weld pool and the factors affecting the formation of the weld bead profile.

\section{Experimental procedure}

The as-received base material (BM) provided by Tata Steel, was $13 \mathrm{~mm}$ thick S700 HSLA steel in the form of hot rolled strips (chemical composition: $0.068 \% \mathrm{C}, 1.476 \% \mathrm{Mn}, 0.009 \% \mathrm{Mn}, 0.009 \% \mathrm{P}$, 
$0.001 \% \mathrm{~S}, 0.05 \% \mathrm{Si}, 0.073 \% \mathrm{Al}, 0.495 \% \mathrm{Cr}, 0.19 \% \mathrm{Mo}, 0.03 \% \mathrm{Nb}, 0.044 \%$ $\mathrm{V}, 0.0018 \% \mathrm{~B}, 0.0045 \% \mathrm{~N}$ and balance $\mathrm{Fe}$ ), which had been rapidly water cooled to low temperature producing a bainitic microstructure.

A continuous wave (CW) fibre laser (IPG YLR-16000) was used in these laser welding experiments with a maximum available laser power of $16 \mathrm{~kW}$ and a beam parameter product (BPP) of $10 \mathrm{~mm}$ mrad delivered with an optical fibre, $300 \mu \mathrm{m}$ in diameter. The laser beam emitted from the optical fibre was collimated by a lens with a $150 \mathrm{~mm}$ focal length and then focused onto the specimen surface using a lens with a $400 \mathrm{~mm}$ focal length. The measured focus size and Rayleigh length were 0.8 and $15 \mathrm{~mm}$, respectively. The laser head was mounted on a 6-axis KUKA robot. A schematic representation of the laser welding setup for $1 \mathrm{G}$ and $2 \mathrm{G}$ welding positions is shown in Fig. 1.

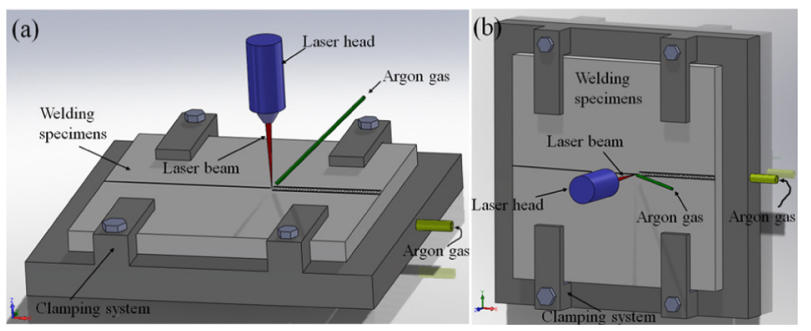

Fig. 1. Schematic representation of the laser welding setup for (a) $1 \mathrm{G}$ welding position and (b) $2 \mathrm{G}$ welding position.

The top and the back surfaces of the specimen were shielded using argon gas to protect the molten weld pool during welding, using flow rates between 8 and $12 \mathrm{l} / \mathrm{min}$.

A significant number of preliminary welding trials on the $13 \mathrm{~mm}$ thick S700 HSLA steel plates helped to establish that it was beneficial to set the focal position below the top surface of the specimens, in order to minimise the melt sagging problem, which was in agreement with earlier published results [7]. A focal position of $8 \mathrm{~mm}$ below the top surface of the specimens was found to work well, and thus was employed in the welding experiments for both $1 \mathrm{G}$ and $2 \mathrm{G}$ welds. The Design Expert 7.0 software package was used for designing the experiments. The experiments were designed based on two welding variables (laser power and welding speed), employing five levels for each. A response surface method (RSM) was used to identify the most significant factors influencing the weld bead characteristics, including penetration depth and the extent of undercut.

After laser welding, specimens were cut from the welded plates on a transverse section with respect to the welding direction. The specimens were subsequently ground and polished using an automatic polishing machine, followed by etching in a solution of $2 \%$ Nital for about $2 \mathrm{~s}$. The macrostructure of each joint was examined using an optical microscope (KEYENCE VHX-500F) and microstructures were examined using a Philips XL 30 scanning electron microscope (SEM).

\section{Results}

A set of 11 laser welding experiments in both the $1 \mathrm{G}$ and $2 \mathrm{G}$ positions was performed using various welding parameters, according to the design matrix shown in Table 1. Using the 1G welding position one can achieve a deeper penetration depth compared with that for the $2 \mathrm{G}$ welding position when using the same welding parameters. However, the undercut depth was also larger for the $1 \mathrm{G}$ welds, as seen from the results in Table 1 .

It was found from the welding trials that weld pool sagging is one of the characteristics of $13 \mathrm{~mm}$ thick welds in S700 steel in the $1 \mathrm{G}$ position. A periodic sagging defect was generated on the weld root side. The transition from a partially penetrated weld to a fully penetrated weld with weld pool sagging was dramatic and resulted from small changes in welding parameters. Indeed, it was very difficult to obtain a good full penetration weld without melt
Table 1

Statistical model design matrix and responses.

\begin{tabular}{|c|c|c|c|c|c|c|}
\hline \multirow[t]{3}{*}{ Run } & \multirow{2}{*}{\multicolumn{2}{|c|}{ Factors }} & \multirow{2}{*}{\multicolumn{2}{|c|}{$\frac{1 \mathrm{G} \text { welding position }}{\text { Responses }}$}} & \multirow{2}{*}{\multicolumn{2}{|c|}{$\begin{array}{l}\text { 2G welding position } \\
\text { Responses }\end{array}$}} \\
\hline & & & & & & \\
\hline & $\begin{array}{l}\text { Power } \\
(\mathrm{kW})\end{array}$ & $\begin{array}{l}\text { Welding } \\
\text { speed } \\
(\mathrm{m} / \mathrm{min})\end{array}$ & $\begin{array}{l}\text { Penetration } \\
\text { depth } \\
(\mathrm{mm})\end{array}$ & $\begin{array}{l}\text { Undercut } \\
\text { depth } \\
(\mathrm{mm})\end{array}$ & $\begin{array}{l}\text { Penetration } \\
\text { depth } \\
(\mathrm{mm})\end{array}$ & $\begin{array}{l}\text { Undercut } \\
\text { depth } \\
(\mathrm{mm})\end{array}$ \\
\hline 1 & 11.5 & 1.26 & 13 & 2.68 & 10.7 & 0.35 \\
\hline 2 & 10 & 1.8 & 8.89 & 0.68 & 8.27 & 0.47 \\
\hline 3 & 10 & 0.72 & 13 & 2.64 & 11.73 & 0.43 \\
\hline 4 & 11.5 & 1.26 & 13 & 2.74 & 10.9 & 0.31 \\
\hline 5 & 13.6 & 1.26 & 13 & 2.20 & 13 & 2.09 \\
\hline 6 & 9.4 & 1.26 & 9.08 & 0.30 & 8.89 & 0.23 \\
\hline 7 & 11.5 & 0.5 & 13 & 4.62 & 13 & 0.24 \\
\hline 8 & 11.5 & 1.26 & 13 & 2.54 & 10.2 & 0.27 \\
\hline 9 & 13 & 1.8 & 13 & 4.33 & 10.4 & 0.24 \\
\hline 10 & 11.5 & 2.02 & 9.8 & 0.43 & 9.45 & 0.35 \\
\hline 11 & 13 & 0.72 & 13 & 1.53 & 13 & 0.23 \\
\hline
\end{tabular}

sagging using the $1 \mathrm{G}$ welding position in $13 \mathrm{~mm}$ thick $\mathrm{S} 700$ steel. Weld pool sagging leads to deep undercut on the top surface of the weld. Kawahito and Katayama [12] reported that the laser welding process window for the production of sound welds was very narrow using the $1 \mathrm{G}$ welding position when welding thick section 304 stainless steel plates. The minimisation of weld pool sagging is one of the most important challenges when one is seeking to avoid undercut defects in single pass laser welding of thick section materials.

Fig. 2 shows the interactions between laser power and welding speed in affecting the penetration depth for the $1 \mathrm{G}$ and $2 \mathrm{G}$ welding positions. There is a large set of welding parameters (high power and low welding speed) that can be used to achieve full penetration for the $1 \mathrm{G}$ welding position, as seen in the red region in Fig. 2a. However, melt sagging was unavoidable for full penetration welds when using the $1 \mathrm{G}$ welding position. In contrast, a smaller range of welding parameters can be used to obtain full penetration using the $2 \mathrm{G}$ position (Fig. $2 \mathrm{~b}$ ), without sagging, as will be seen later.
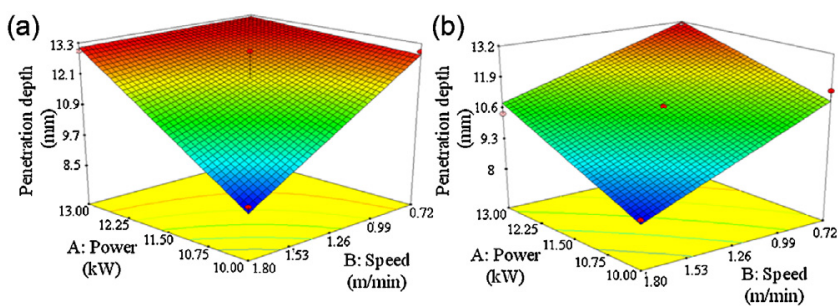

Fig. 2. Contour map showing the effects of laser power and welding speed on the penetration depth, (a) $1 \mathrm{G}$ position, (b) $2 \mathrm{G}$ position.

The interactions between laser power and welding speed in affecting the undercut depth for the $1 \mathrm{G}$ and $2 \mathrm{G}$ welding positions are shown in Fig. 3. Changes in welding parameters have a big effect on the undercut depth in the $1 \mathrm{G}$ welding position, as seen in Fig. 3a, while changes in welding parameters have a smaller effect on the undercut depth when using the $2 \mathrm{G}$ position, as seen in Fig. 3b. Much deeper undercut was formed in the $1 \mathrm{G}$ welding position than in the $2 \mathrm{G}$ welding position when using the same welding parameters.
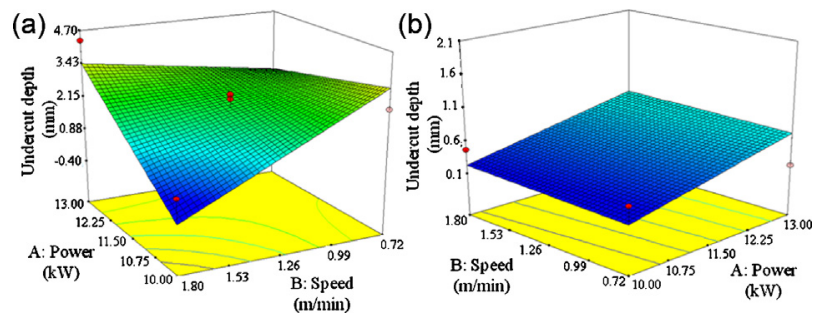

Fig. 3. Contour map showing the effects of laser power and welding speed on the undercut depth, (a) $1 \mathrm{G}$ position, (b) $2 \mathrm{G}$ position. 
In the parameter optimisation investigation, a numerical multiple response optimisation criterion was used to reach the maximum penetration depth $(13 \mathrm{~mm})$ and a minimum in the undercut depth in order to improve the weld quality. In order to satisfy multi-objective optimisation, the desirability function is defined by the geometric mean of all individual desirabilities that range from 0 for the least desirable settings to 1 for the most desirable process settings [13]. The function is defined as [13]:

$\delta=\left(\prod_{i=1}^{n} d_{i}\right)^{\frac{1}{n}}$

This equation represents the overall desirability function, where $\delta$ is the overall desirability, $n$ is the number of responses and $d_{i}$ is the $i$ th response desirability value. In this research, both numerical and graphical optimisation approaches were used by selecting the desired goals for each factor and response.

The optimised welding parameters for both the $1 \mathrm{G}$ and $2 \mathrm{G}$ welding positions were $13 \mathrm{~kW}$ and $0.72 \mathrm{~m} / \mathrm{min}$, and these were used on the specimens in each case. A comparison of the top and back weld appearances, and weld cross sections using these two groups of optimised welding parameters are shown for each position in Fig. 4. It can be seen that sound welds were obtained using the $2 \mathrm{G}$ welding position with the above optimised welding parameters, while periodic sagging was observed on the back of the weld for the $1 \mathrm{G}$ welding position. It was found that the microstructure in the weld for both the $1 \mathrm{G}$ and $2 \mathrm{G}$ positions was bainite, as shown in Fig. 5a. The microstructure in the heat affected zone (HAZ) for both the $1 \mathrm{G}$ and $2 \mathrm{G}$ positions was bainite mixed with martensite, as shown in Fig. 5b. Several welding trials were carried out in the hope of obtaining sound welds using the $1 \mathrm{G}$ welding position. However, we were unable to obtain sound welds (due to either lack of penetration or melt sagging).

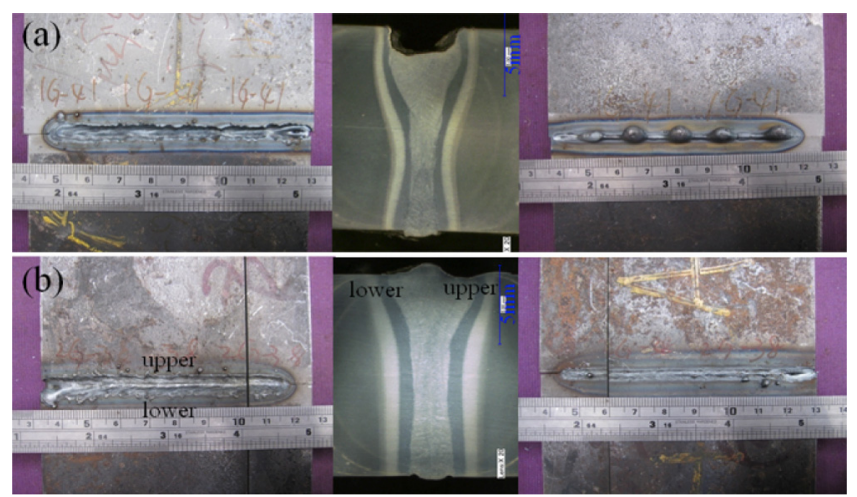

Fig. 4. Top weld appearance, weld cross section and weld underside appearance using optimised welding parameters in the $1 \mathrm{G}$ and $2 \mathrm{G}$ positions $(13 \mathrm{~kW}, 0.72 \mathrm{~m} /$ min), (a) $1 \mathrm{G}$ position, (b) $2 \mathrm{G}$ position.

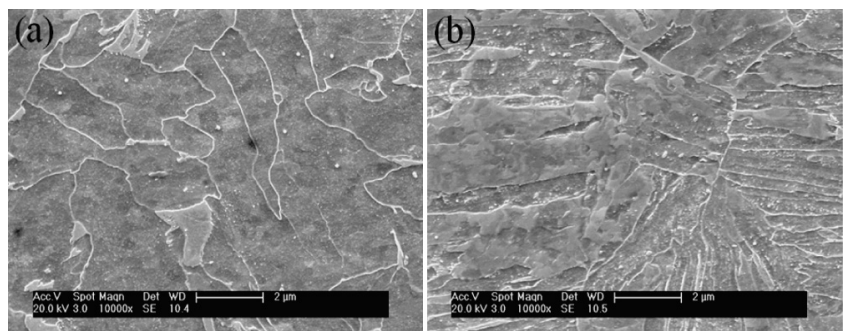

Fig. 5. The microstructures of the weld and HAZ, (a) weld, (b) HAZ.

\section{Discussion}

The results in Table 1 demonstrate that using the $1 \mathrm{G}$ welding position can lead to a deeper penetration depth when compared with the $2 \mathrm{G}$ position, when using the same welding parameters. This may be because, in the $1 \mathrm{G}$ position, gravity is acting in the same direction as the laser beam, which aids the flow of metal towards the lower part of the weld pool. In contrast, gravity was acting in a direction that was perpendicular to the penetration direction for the $2 \mathrm{G}$ welding position. Under the action of gravity, the heat transfer from the high temperature metal could be biased in a direction that is perpendicular to the beam axis. A schematic representation of the pressure balance in the weld pool for both the $1 \mathrm{G}$ and $2 \mathrm{G}$ welding positions is shown in Fig. 6.

(a)
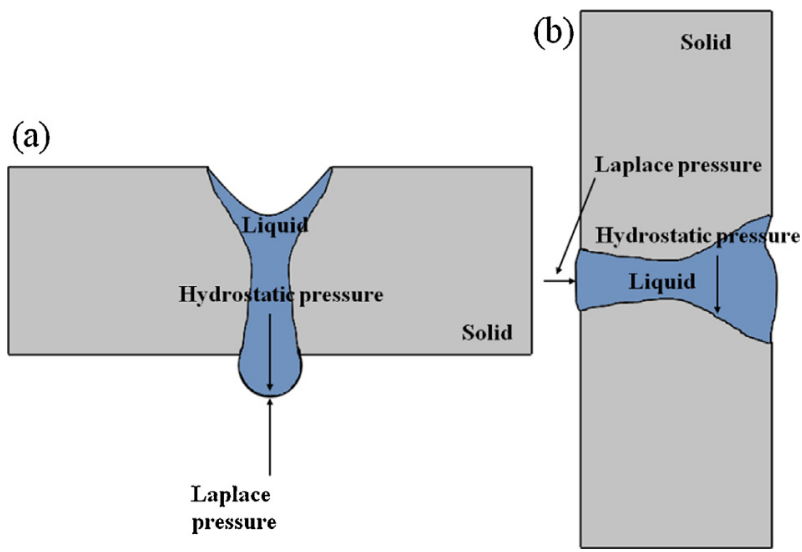

Fig. 6. Schematic representation of the pressure balance in the weld pool, (a) 1G position, (b) 2G position.

The undercut depth for the $1 \mathrm{G}$ welding position was deeper than that for the $2 \mathrm{G}$ welding position with the same welding parameters. This may be attributable to a higher degree of fluid flow, driven by gravity, towards the root of the weld. For the full penetration $1 \mathrm{G}$ welds, the drop out of metal on the underside of the weld led to deeper undercut on the top side of the weld.

Three-dimensional computational fluid dynamic (CFD) modelling was performed in order to understand the dynamic forces within the weld pool, and the weld geometry that is formed with the optimised welding parameters. This was performed using FLUENT software. In the CFD model, the Navier-Stokes mass, energy and momentum balance equations were used:

Mass conservation equation:

$\nabla \cdot \mathrm{v}=0$

where $v$ is the velocity vector.

Navier-Stokes equation:

$\frac{\partial \mathrm{v}}{\partial t}+\mathrm{v} \cdot \nabla \mathrm{v}=-\frac{1}{\rho} \nabla p+v \nabla^{2} \mathrm{v}-\mathrm{Kv}+\mathrm{g}$

where $\rho$ is the fluid density, $p$ is the pressure, $v$ is the dynamic viscosity, $K$ is the drag coefficient for a porous media model in the mushy zone and $g$ is the gravitational acceleration.

Energy conservation equation:

$\frac{\partial h}{\partial t}+\mathrm{v} \cdot \nabla \mathrm{h}=\frac{1}{\rho} \nabla \cdot(\mathrm{k} \nabla \mathrm{T})$

where $h$ is the enthalpy, $k$ is the thermal conductivity, and $T$ is the temperature.

The fluid flow in the weld pool is primarily driven by the combination of surface tension and the buoyancy force. The material properties used for the simulation were obtained from the literature [14,15].

The boundary condition used in this study was as follows: Marangoni shear stresses at the metal-air surface due to surface tension variations with temperature:

$\eta \frac{\partial u}{\partial z}=\frac{\partial \gamma}{\partial T} \frac{\partial T}{\partial x}, \eta \frac{\partial v}{\partial z}=\frac{\partial \gamma}{\partial T} \frac{\partial T}{\partial y}$

where $\gamma$ is the surface tension and $u=(u, v, w)$ are the velocity components in the corresponding directions. The surfaces were also subject to a slip condition. The inlet temperature was set to 
room temperature. The velocity in the normal direction at the inlet boundary was set to be constant. The symmetry plane was adiabatic and flow in the wall-normal direction was not allowed.

Fig. 7 shows the calculated weld pool profiles for the $1 \mathrm{G}$ and $2 \mathrm{G}$ positions. When the surface tension is not high enough to balance the hydrostatic pressure and the recoil pressure, melt sagging occurs in the $1 \mathrm{G}$ position, and the molten metal drops out, so that an undercut can form after solidification (Fig. 7a). However, in the $2 \mathrm{G}$ position, gravity is acting in a direction perpendicular to the penetration direction. This enables the surface tension to balance the pressure in the molten pool. The molten metal remains stable in the weld pool with full penetration, but without melt sagging (Fig. 7b). A full penetration weld with a very small undercut $(0.2 \mathrm{~mm})$ can form. A comparison of the measured weld appearances and cross sections for the $1 \mathrm{G}$ and $2 \mathrm{G}$ welding positions in Fig. $4 a$ and b, with the simulated weld pools in Fig. $7 \mathrm{a}$ and $b$, reveals very good agreement.

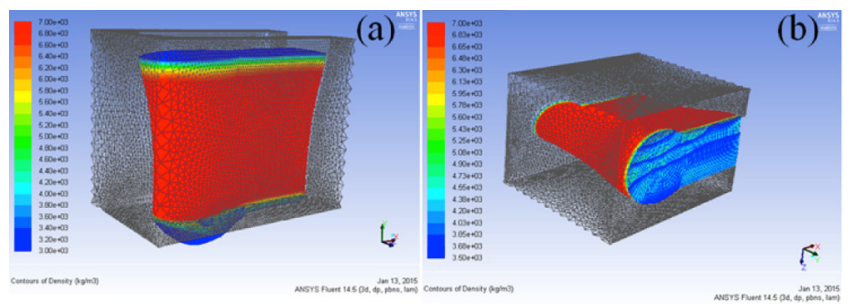

Fig. 7. Simulated fluid flow and the weld pool dynamic profiles, (a) $1 G$ position, (b) $2 \mathrm{G}$ position.

The simulated longitudinal section and the cross-section of the dynamic weld pool for the $1 \mathrm{G}$ and $2 \mathrm{G}$ positions, respectively, are presented in Fig. 8. There is a high pressure at the bottom of the molten pool for the $1 \mathrm{G}$ position, with a value of approximately $1000 \mathrm{~Pa}$, as seen in Fig. 8a. This result is close to the hydrostatic pressure of the melt column, $p_{h s}$, according to:

$p_{h s}=\rho g h$

where $\rho, g$ and $h$ are the density, the gravitational acceleration and the height of the column of molten metal, respectively. Using the density of molten steel (approximately $7.6 \times 10^{3} \mathrm{~kg} / \mathrm{m}^{3}$ ) [14,15], the calculated hydrostatic pressure of the melt column is approximately $970 \mathrm{~Pa}$. The simulated pressure at the bottom of the molten pool $(\sim 1000 \mathrm{~Pa})$ for the $1 \mathrm{G}$ position in Fig. $8 \mathrm{a}$ is very close to the calculated hydrostatic pressure, which validates the simulated results from another perspective.

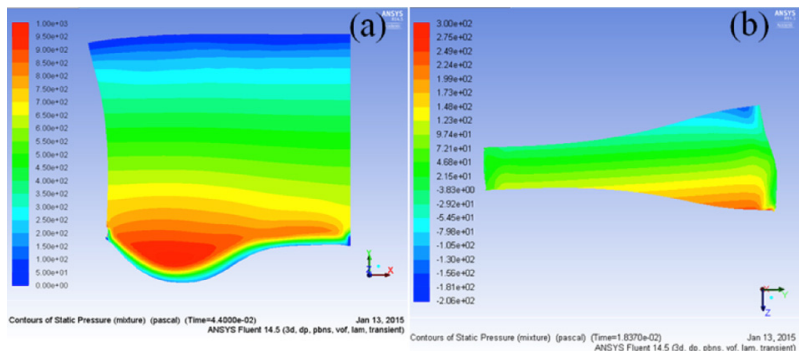

Fig. 8. Simulated fluid flow and pressure distribution in the weld pool, (a) longitudinal section of the $1 \mathrm{G}$ weld pool, (b) cross section of $2 \mathrm{G}$ weld pool.

From the perspective of the Laplace pressure, $p_{\gamma}$, at the curved and sagging root surface of the weld pool,

$p_{\gamma}=\frac{\gamma}{r}$

where $\gamma$ is the surface tension coefficient of the molten metal and $r$ is the radius of the sagging root surface. For carbon steel, the surface tension can reach a value of approximately $1.65 \mathrm{~N} / \mathrm{m}$ $[14,15]$ and the subsequent value of the Laplace pressure for the experimentally observed sagging root with a $2.5 \mathrm{~mm}$ radius can be up to $660 \mathrm{~Pa}$, which is lower than the hydrostatic pressure of approximately $1000 \mathrm{~Pa}$ for the $13 \mathrm{~mm}$ thick S700 steel (without considering the recoil pressure) which drives the sagging of the molten pool.

The molten metal in the sample welded in the $2 \mathrm{G}$ position has a lower pressure (Fig. 8b). There is a relatively high pressure $(\sim 300 \mathrm{~Pa})$ in the lower region of the molten pool due to the influence of gravity acting on the pool, and the resulting hydrostatic pressure. However, this relatively high pressure is located at the boundary between the molten pool and solid material (the fusion line). As such, this pressure can be sustained by solid material. Moreover, due to the movement of the molten metal near the top of the pool under the influence of gravity, there is a small cavity generated at this location, which results in a negative pressure $(\sim-100 \mathrm{~Pa})$. The central region of the molten pool has a low pressure of $\sim 30 \mathrm{~Pa}$. This low pressure in the $2 \mathrm{G}$ molten pool makes it feasible for surface tension to balance this pressure during welding, thereby stabilising the weld pool.

\section{Conclusions}

High quality single-pass autogenous laser welds in $13 \mathrm{~mm}$ thick S700 steel have been demonstrated using the $2 \mathrm{G}$ welding position. Indeed, this work has demonstrated that gravity-driven weld pool drop-out, which is associated with the welding of thick plates, can be prevented by taking advantage of the $2 \mathrm{G}$ welding position. It was found to be very difficult to obtain high quality welds using the $1 \mathrm{G}$ position, for autogenous single pass laser welding, without employing any other support for the weld pool. The CFD modelling has shown that the pressure in the molten pool is lower when using the $2 \mathrm{G}$ welding position.

\section{References}

[1] Oñoro JRC (1997) Fatigue Behaviour of Laser Welds of High-Strength LowAlloy Steels. Journal of Materials Processing Technology 68:68-70.

[2] Yan W, Zhu L, Sha W, Shan Y-Y, Yang K (2009) Change of Tensile Behavior of a High-Strength Low-Alloy Steel With Tempering Temperature. Materials Science and Engineering A 517:369-374.

[3] Takasawa K, Ikeda R, Ishikawa N, Ishigaki R (2012) Effects of Grain Size and Dislocation Density on the Susceptibility to High-Pressure Hydrogen Environment Embrittlement of High-Strength Low-Alloy Steels. International Journal of Hydrogen Energy 37:2669-2675.

[4] Li L, Eghlio R, Marimuthu S (2011) Laser Net Shape Welding. CIRP Annals Manufacturing Technology 60:223-226.

[5] Schmidt M, Otto A, Kägeler C (2008) Analysis of YAG Laser Lap-Welding of Zin Coated Steel Sheets. CIRP Annals - Manufacturing Technology 57:213-216.

[6] Ready JF, Farson DF, Feeley T (2001) LIA Handbook of Laser Materials Processing Laser Institute of America, Springer-Verlag, New York. ISBN 3-540-41770-2.

[7] Bachmann M, Avilov V, Gumenyuk A, Rethmeier M (2014) Experimental and Numerical Investigation of an Electromagnetic Weld Pool Control for Laser Beam Welding. Physics Procedia 56:515-524.

[8] Henderson SKI (1976) Investigation of Different Methods of Protecting the Molten Pool in Narrow-Gap Welding of a Structural Steel for Nuclear Reactor Use. Welding and Cutting 28:291-293.

[9] Jones LP, Aubert P, Avilov V, Coste F, Daenner W, Jokinen T, Nightingale KR, Wykes M (2003) Towards Advanced Welding Methods for the ITER Vacuum Vessel Sectors. Fusion Engineering and Design 69:215-220.

[10] Hideki Okado TN, Wani F, Hayakawa Y, Suzuki S, Yasuda K (2001) Thick Plate Welding With the High Power Combined Laser Beam, Lasers and ElectroOptics, 2001. CLEO/Pacific Rim 2001. The 4th Pacific Rim Conference, vol. 1, I316-I-317.

[11] Fumio Wani TN, Hayakawa A, Suzuki S, Yasuda K (2002) High-Power COIL and YAG Laser Welding. Proceedings of SPIE 4631:128-136.

[12] Kawahito MMY, Katayama S (2009) High Quality Welding of Stainless Stee With $10 \mathrm{~kW}$ High Power Fibre Laser. Science and Technology of Welding and Joining 14:288-294.

[13] Stephen Leigh KS, Li L, Grafton-Reed C (2009) Martyn Cuttell Statistical Analysis of Recast Formation in Laser Drilled Acute Blind Holes in CMSX-4 Nickel Superalloy. The International Journal of Advanced Manufacturing Technology 43:1094-1105.

[14] Cho W-I, Na S-J, Thomy C, Vollertsen F (2012) Numerical Simulation of Molten Pool Dynamics in High Power Disk Laser Welding. Journal of Materials Processing Technology 212:262-275.

[15] Jyrki Mieti'inen SL (1994) Calculation of Thermophysical Properties of Carbon and Low Alloyed Steels for Modeling of Solidification. Processes Metallurgical and Materials Transactions B 25B:909-916. 